Revista

Ibero-Americana

de Estratégıa
FATORES CONDICIONANTES DA IMPLEMENTAÇÃO DE ESTRATÉGIAS

COMPETITIVAS E COOPERATIVAS: O CASO DAS INDÚSTRIAS DE JOIAS DE GUAPORÉ-RS

FACTORS CONDITIONING THE IMPLEMENTATION OF COOPERATIVE AND COMPETITIVE STRATEGIES: THE CASE OF INDUSTRIES OF JEWELRY GUAPORÉRS STATE

CONDICIONANTES DE LA APLICACIÓN DE LAS ESTRATEGIAS DE COOPERACIÓN Y COMPETITIVA: EL CASO DE LA INDUSTRIA DE JOYERÍA GUAPORÉ-RS

\title{
Cristina Gallon
}

Bacharel em Administração pela Universidade de Passo Fundo - UPF

E-mail: cristinagallon@gmail.com (Brasil)

\section{Paloma de Mattos}

Doutoranda em Agronegócios pela Universidade Federal do Rio Grande do Sul - UFRGS

E-mail: palomattos@hotmail.com (Brasil) 
Fatores Condicionantes da Implementação de Estratégias Competitivas e Cooperativas: O Caso das Indústrias de Joias de Guaporé-RS

\title{
FATORES CONDICIONANTES DA IMPLEMENTAÇÃO DE ESTRATÉGIAS COMPETITIVAS E COOPERATIVAS: O CASO DAS INDÚSTRIAS DE JOIAS DE GUAPORÉ-RS
}

\section{RESUMO}

Este estudo tem como objetivo identificar e analisar os fatores condicionantes do desenvolvimento de estratégias competitivas e cooperativas nas indústrias de joias de Guaporé-RS. Os procedimentos metodológicos empregados neste estudo são explicados pela pesquisa do tipo qualitativa e exploratória, sendo os dados coletados por meio de questionário enviado para as empresas produtoras de joias escolhidas aleatoriamente. Os dados foram analisados pela transcrição das respostas dos questionários e organizados em quadros para uma melhor compreensão. Os resultados indicam que as empresas utilizam estratégias competitivas e cooperativas que são delineadas pensando em produzir produtos com preços baixos, diferenciados, especialmente por estarem num ambiente pressionado por produtos importados que disputam a preferência dos consumidores.

Palavras-chave: Competição; Cooperação; Estratégias; Joias.

\author{
FACTORS CONDITIONING THE IMPLEMENTATION OF COOPERATIVE AND \\ COMPETITIVE STRATEGIES: THE CASE OF INDUSTRIES OF JEWELRY GUAPORÉ- \\ RS STATE
}

\begin{abstract}
This study aims to identify and analyze factors that influence the development of competitive and cooperative strategies in the industry of jewelry of Guaporé-RS. The methodological procedures employed in the study are explained by qualitative and exploratory studies, along with data collected through a questionnaire presented to randomnly chosen producers of jewelry and semi jewelry. Data were analyzed using the transcription of the questionnaire responses and organized in tables for better understanding. The results indicate that firms using strategies that are competitive and exercise cooperative thinking result in producing low-costs. This result is important due to the fact that this industry is under pressure to compete for consumers from imported products.
\end{abstract}

Keywords: Strategies; Competition; Cooperation; Jewelry.

Revista Ibero-Americana de Estratégia - RIAE, São Paulo, v. 11, n. 2, p. 34-69, mai./ago. 2012. 
CONDICIONANTES DE LA APLICACIÓN DE LAS ESTRATEGIAS DE COOPERACIÓN Y COMPETITIVA: EL CASO DE LA INDUSTRIA DE JOYERÍA GUAPORÉ-RS

\section{RESUMEN}

Este estudio tiene como objetivo identificar y analizar los factores que influyen en el desarrollo de estrategias cooperativas y competitivas en la industria de la joyería Guaporé-RS. Los procedimientos metodológicos utilizados en este estudio se explica por el estudio cualitativo y exploratorio, con datos recogidos a través de un cuestionario enviado a las empresas que fabrican joyas elegido al azar. Los datos fueron analizados por la transcripción de las respuestas a los cuestionarios y organizados en tablas para una mejor comprensión. Los resultados indican que las empresas utilizan estrategias competitivas y cooperativas que están delineados pensando en la producción de productos con precios bajos y diferenciados, sobre todo en un ambiente al ser presionado por los productos importados que compiten por la preferencia del consumidor.

Palabras-clave: Competencia, Cooperación; Estrategias; Joyas. 
Fatores Condicionantes da Implementação de Estratégias Competitivas e Cooperativas: O Caso das Indústrias de Joias de Guaporé-RS

\section{INTRODUÇÃO}

A competitividade entre as indústrias se mostra crescente no cenário atual. Com o surgimento de novos produtos e tecnologias, as empresas vislumbram um ambiente de competição cada vez mais denso. Este ambiente exige que as empresas se posicionem estrategicamente, de forma correta, para que possam permanecer e crescer no mercado.

Neste contexto, a escolha da estratégia é de crucial importância para uma empresa. Hitt, Ireland e Hoskisson (2008) afirmam que quando uma empresa opta por uma estratégia, ela está escolhendo suas alternativas para competir. Assim, a estratégia revela onde a empresa deseja chegar e as ações que irá desenvolver para alcançar seus objetivos.

A palavra-chave que identifica este ambiente competitivo é a mudança. Ao longo do tempo, as empresas passaram a enxergar além de suas paredes e perceber que a visão antiga de competição descabida já não era mais tão eficaz.

Antigamente se pensava que para as organizações serem bem-sucedidas, tinham de trabalhar isoladas, protegendo-se das demais para obter vantagens competitivas no mercado. Atualmente, a visão de cooperação entre as empresas está mudando, e o enfoque nesta área tem-se constituído em uma alternativa para lidar com o novo contexto em que se inserem as organizações.

Neste panorama, surge então uma nova forma de concepção: a cooperação para competir, a fusão dos termos cooperação e competição. Na chamada coopetição, a cooperação entre concorrentes surge como alternativa para atender as exigências competitivas do mercado, uma vez que é a escolha da estratégia que determina quem permanece competindo e quem morre.

No município de Guaporé, com aproximadamente 21 mil habitantes, localizado na parte Nordeste do Rio Grande do Sul, encontram-se várias empresas instaladas. A competitividade no local é forte, principalmente no setor joalheiro onde está concentrada a maioria das organizações.

O prestígio nacional e internacional dos produtos guaporenses trouxe fama à cidade, estimulando um número cada vez maior de empresas a se instalarem no município. Assim, constituiu-se o conglomerado de diferentes empresas que atuam na produção da joia com reconhecimento nacional em termos de organização. De acordo com a Secretaria de Indústria e Comércio de Guaporé, existem no local 138 indústrias que produzem e comercializam joias e concorrem no mercado adotando diferentes tipos de estratégias.

O cenário organizacional joalheiro local é constituído por empresas envolvidas nas diferentes etapas do ciclo produtivo. A maioria destas empresas é considerada micro ou pequena, 
em termos de porte. Estão instaladas em um ambiente que apresenta forte competição, oferecendo também fácil acesso à matéria-prima e aos serviços terceirizados.

Entretanto, é interessante compreender como funciona o ambiente de competição entre as empresas, já que coexistem no mesmo local vários concorrentes que produzem produtos iguais ou semelhantes para mercados idênticos. É pertinente avaliar também a existência ou não de ações cooperativas no alcance de benefícios mútuos.

Neste sentido, este estudo tem como objetivo identificar e analisar os fatores condicionantes do desenvolvimento de estratégias competitivas e cooperativas nas indústrias de joias de GuaporéRS. Assim, as ações estratégicas promovidas pelas empresas se caracterizam como objeto de análise para avaliar a dinâmica competitiva e cooperativa do setor. A compreensão dos motivos que levam a empresa à escolha da estratégia também são de relevante importância. A compreensão destes fatores contribuirá para avaliar o ambiente competitivo local.

\section{REVISÃO DA LITERATURA}

Dado um ambiente de competição, a mudança, a elaboração e implementação de estratégias se tornaram condição fundamental para as empresas do segmento joalheiro. A utilização de estratégias eficazes permitem às indústrias de produção de joias entender as mudanças do ambiente e atingir um desempenho superior na competição. Por conseguinte, existe uma necessidade de discutir a tipologia de estratégias competitivas e cooperativas apresentadas pelos autores teóricos que são apresentadas a seguir.

\subsection{ESTRATÉGIAS COMPETITIVAS}

Mintzberg et al. (2006) mencionam que estratégia competitiva é a arte de criar ou explorar as vantagens mais fortes, duradouras e mais difíceis de duplicar. A estratégia competitiva está voltada ao que a empresa pode fazer melhor do que seus concorrentes ou, pelo menos, para se igualar a eles.

Para Porter (1989), existem duas formas básicas de vantagem competitiva: o menor custo ou a diferenciação. O menor custo é a capacidade que uma empresa tem de produzir um bem a custos menores do que seus concorrentes. A diferenciação é a capacidade de apresentar um produto com valor agregado, seja em termos de qualidade, serviços ou características exclusivas. Uma empresa pode apresentar ao mesmo tempo as duas estratégias, embora seja muito difícil de conseguir.

Revista Ibero-Americana de Estratégia - RIAE, São Paulo, v. 11, n. 2, p. 34-69, mai./ago. 2012. 
Fatores Condicionantes da Implementação de Estratégias Competitivas e Cooperativas: O Caso das Indústrias de Joias de Guaporé-RS

Hitt, Ireland e Hoskisson (2008) mencionam que as Estratégias no Nível de Negócios são aquelas desenvolvidas por uma empresa, utilizando suas competências essenciais, a fim de obter vantagem competitiva em mercados de produtos específicos, sendo elas:

- estratégia de liderança em custo é aquela que foca na produção de bens e serviços, com características aceitáveis pelos clientes, a um menor custo do que o dos concorrentes. Para isso, as empresas estão sempre procurando exercer suas atividades a um custo menor, tentando, ao mesmo tempo, manter níveis competitivos de diferenciação.

Nas empresas que adotam a estratégia de liderança em custo, as decisões da produção podem considerar as funções da gestão de operações e da contabilidade como elementos importantes, e que podem ser desenvolvidas em conjunto com o marketing com o intuito de reduzir a ineficiência e a minimização dos custos para se alcançar o objetivo estratégico (Merlo, Lukas \& Whitwell, 2012).

- estratégia de diferenciação tem foco na produção de bens e serviços, a um custo aceitável e que sejam diferenciados na percepção dos clientes, tornando-se importante adquiri-los. Esta estratégia visa atingir clientes que percebam o valor criado no produto em relação aos da concorrência e que valorizem características diferenciadas em detrimento do baixo custo.

Segundo Merlo, Lukas \& Whitwell (2012), quanto mais uma empresa depende de uma estratégia de diferenciação, o mais provável é que ela foque o marketing como um recurso estratégico. Portanto, quanto maior for o destaque para uma estratégia de diferenciação, mais forte será a ligação entre a reputação do marketing e sua influência.

- estratégia de foco é aquela que visa atender a um determinado segmento competitivo ou nicho de mercado. Exemplos de segmentos de mercados são: (1) um determinado grupo de compradores, como os aposentados, (2) um segmento diferente de uma linha de produto como uma tintura de cabelo para quem pinta cabelo em casa ou (3) um mercado geográfico específico, o sul do Brasil, por exemplo.

Revista Ibero-Americana de Estratégia - RIAE, São Paulo, v. 11, n. 2, p. 34-69, mai./ago. 2012. 
Na percepção de Fuchs e Diamantopoulos (2010), a decisão de escolher a estratégia de foco mais eficaz constitui um grande desafio para os profissionais de marketing, especialmente no que se refere à percepção e escolha dos consumidores por determinado produto ou serviço. Para eles, se o posicionamento é eficaz, o potencial para construir marcas poderosas é aumentado, no entanto, se feito incorretamente, também pode resultar em fracasso.

- custos/diferenciação se desenvolve quando uma empresa adota essa estratégia, busca "produzir eficientemente produtos com alguns atributos diferenciados". Aquelas que conseguem fabricar produtos relativamente diferenciados a um custo mais baixo, têm um bom desempenho no mercado e, geralmente, apresentam retornos acima da média.

Tais aspectos são reforçados por Nandakumar, Ghobadian \& O'Regan (2011) ao mencionarem que as evidências empíricas sugerem que a aplicação de uma estratégia integrada pela combinação da liderança em custo e diferenciação é útil para ganhar retornos acima da média.

Outro tipo de estratégia refere-se à diversificação. No ponto de vista de Mintzberg et al. (2006, p.119) “[...]a diversificação refere-se à entrada em algumas áreas de negócios que não estão na mesma cadeia de operações". Para os autores esta diversificação pode ser relacionada, quando o novo negócio possui ligação com o negócio principal da organização; ou não relacionada, quando não possui relação com o negócio principal.

Adicionalmente, Chena e Chang (2012) mencionam que a diversificação tem sido considerada como uma ferramenta essencial para as empresas aumentarem suas margens de lucro e participação de mercado. A obtenção de sinergia entre o produto e a diversificação reside no conhecimento da empresa de como gerenciar melhor a diversificação corporativa de uma forma sinérgica (Liu \& Hsu, 2011).

Nesse aspecto, a Figura 1 sistematiza brevemente os tipos de estratégias competitivas, a fim de facilitar a compreensão dos conceitos mencionados e fornecer uma base para a análise dos dados obtidos na pesquisa.

Revista Ibero-Americana de Estratégia - RIAE, São Paulo, v. 11, n. 2, p. 34-69, mai./ago. 2012. 
Fatores Condicionantes da Implementação de Estratégias Competitivas e Cooperativas: O Caso das Indústrias de Joias de Guaporé-RS

Figura 1 - Estratégias competitivas.

\begin{tabular}{|c|c|c|c|}
\hline \multicolumn{4}{|c|}{ ESTRATÉGIAS COMPETITIVAS } \\
\hline ESTRATÉGIA & OBJETIVO & TIPOS & DESCRIÇÃO \\
\hline \multirow{5}{*}{$\begin{array}{l}\text { ESTRATÉGIA } \\
\text { DE NÍVEL DE } \\
\text { NEGÓCIOS }\end{array}$} & \multirow{5}{*}{$\begin{array}{l}\text { Criar diferenças } \\
\text { entre a posição de } \\
\text { uma empresa e a de } \\
\text { seus concorrentes } \\
\text { em um setor do } \\
\text { mercado. }\end{array}$} & Liderança em custos & $\begin{array}{l}\text { Produção de bens e serviços a um menor custo } \\
\text { do que o dos concorrentes. } \\
\text { Produtos e serviços padronizados que visam } \\
\text { atingir um segmento amplo de mercado. }\end{array}$ \\
\hline & & Diferenciação & $\begin{array}{l}\text { Produção de bens e serviços que sejam } \\
\text { diferenciados na percepção dos clientes. } \\
\text { Ênfase em características diferenciadas em } \\
\text { detrimento ao baixo custo. }\end{array}$ \\
\hline & & $\begin{array}{l}\text { Liderança em custos } \\
\text { focada }\end{array}$ & $\begin{array}{l}\text { Idêntica a estratégia de liderança em custo. } \\
\text { A diferença é o escopo competitivo, uma } \\
\text { abrange todo o mercado e a outra um segmento } \\
\text { estreito do mesmo. }\end{array}$ \\
\hline & & $\begin{array}{l}\text { Diferenciação } \\
\text { focalizada }\end{array}$ & $\begin{array}{l}\text { Idêntica a estratégia de diferenciação. A } \\
\text { diferença é o escopo competitivo, uma abrange } \\
\text { todo o mercado e a outra um segmento estreito } \\
\text { do mesmo. }\end{array}$ \\
\hline & & $\begin{array}{c}\text { Integrada de } \\
\text { liderança em } \\
\text { custos/diferenciação }\end{array}$ & $\begin{array}{l}\text { Produção de bens ou serviços relativamente } \\
\text { diferenciados a um custo mais baixo. }\end{array}$ \\
\hline \multirow{2}{*}{$\begin{array}{l}\text { ESTRATÉGIAS } \\
\text { NO NÍVEL } \\
\text { CORPORATIVO }\end{array}$} & \multirow{2}{*}{$\begin{array}{l}\text { Utilizada para eleger } \\
\text { e administrar um } \\
\text { grupo de diferentes } \\
\text { negócios que } \\
\text { competem em } \\
\text { mercados de } \\
\text { produtos distintos }\end{array}$} & $\begin{array}{c}\text { Diversificação } \\
\text { relacionada }\end{array}$ & $\begin{array}{l}\text { Quando o novo negócio implementado pela } \\
\text { empresa possui ligação com o negócio principal. }\end{array}$ \\
\hline & & $\begin{array}{l}\text { Diversificação não } \\
\text { relacionada }\end{array}$ & $\begin{array}{l}\text { Quando o novo negócio não possui relação com } \\
\text { o negócio principal. }\end{array}$ \\
\hline
\end{tabular}

Fonte: Elaborado com base em Hitt, Ireland e Hoskisson (2008), Mintzberg et al. (2006), Porter (1989), Merlo, Lukas \& Whitwell (2012), Fuchs e Diamantopoulos (2010), Nandakumar, Ghobadian \& O'Regan (2011), Chena e Chang (2012), Liu \& Hsu (2011).

Revista Ibero-Americana de Estratégia - RIAE, São Paulo, v. 11, n. 2, p. 34-69, mai./ago. 2012. 


\subsection{ESTRATÉGIAS DE COOPERATIVAS}

A respeito da cooperação entre as empresas, Furlanetto apud Farias e Ramos (2009) afirmam que entre elas há uma interdependência. Uma organização para manter-se viva e crescer precisa de recursos, e estes recursos raramente são controlados totalmente pela empresa. A partir deste pressuposto, as empresas precisam juntar-se a outras empresas que detém os recursos dos quais necessitam.

Neste sentido, Hitt, Ireland e Hoskisson (2008, p. 246) referem que “[...]uma estratégia de cooperação é uma estratégia em que as empresas trabalham juntas para atingir um objetivo comum”. A cooperação entre as empresas é uma estratégia que, cada vez mais, é formada por concorrentes, sendo usada para criar valor para o cliente. As estratégias de cooperação estão divididas em estratégias de cooperação em nível de negócios; no nível corporativo, internacional e de redes, sendo que as alianças estratégicas são os principais tipos de estratégia de cooperação.

Seguindo a linha de pensamento, Hitt, Ireland e Hoskisson (2008, p.247) ainda afirmam que “[...]aliança estratégica é uma estratégia de cooperação em que as empresas combinam alguns de seus recursos e capacitações para criar uma vantagem competitiva". Na concepção de Mintzberg et al. (2006, p.229) “[...]as alianças garantem às empresas uma oportunidade única para alavancar suas forcas com a ajuda dos parceiros".

Para Hitt, Ireland e Hoskisson (2008), uma estratégia de cooperação no nível de negócios é aquela utilizada por uma empresa para ter um melhor desempenho no mercado de um produto específico. A empresa junta suas capacitações e recursos com um ou mais parceiros porque acredita que criará vantagens competitivas que, sozinha, não conseguiria criar e que estas vantagens levarão ao sucesso no mercado de produtos distintos.

Outro tipo de estratégia cooperativa são as alianças estratégicas complementares. Na visão de Hitt, Ireland e Hoskisson (2008, p.251), ela se desenvolve quando "[...]as empresas compartilham alguns de seus recursos e capacitações de formas complementares, com a finalidade de desenvolver vantagens competitivas”. Elas ainda podem ser verticais e ou horizontais: (a) alianças estratégicas complementares verticais são aquelas onde as empresas compartilham recursos e capacitações em diferentes etapas da cadeia de valor, com um fornecedor, por exemplo, e, geralmente, são usadas para se adaptar às mudanças ambientais; (b) alianças estratégicas complementares horizontais ocorrem quando as empresas compartilham recursos e capacitações na mesma etapa da cadeia de valor e utilizam esta estratégia para focar as oportunidades de mercado de um produto no longo prazo.

Revista Ibero-Americana de Estratégia - RIAE, São Paulo, v. 11, n. 2, p. 34-69, mai./ago. 2012. 
Fatores Condicionantes da Implementação de Estratégias Competitivas e Cooperativas: O Caso das Indústrias de Joias de Guaporé-RS

Outro tipo de estratégia de cooperação no nível de negócios é a estratégia de reação à concorrência. Nesse caso, as alianças estratégicas são usadas para atacar e reagir a ataques de rivais concorrentes. Temos ainda a estratégia de redução das incertezas que são utilizadas primordialmente em mercados novos ou de ciclos rápidos e na criação e no estabelecimento de novos produtos e tecnologias, com o intuito de proteger a empresa contra riscos e incertezas (Hitt, Ireland, \& Hoskisson, 2008).

E, concluindo as estratégias cooperativas de nível de negócios temos, de acordo com Hitt, Ireland e Hoskisson (2008), a estratégia de redução da concorrência que é representada pelos conluios. De acordo com os autores “[...]em um conluio, duas ou mais empresas cooperam para aumentar os preços acima do nível totalmente competitivo” (p.246). Os conluios apresentam características diferentes das alianças estratégicas, pois são geralmente vistos como uma forma ilegal de estratégia de cooperação. Existem dois tipos de conluio: o explícito, em que as empresas fazem negociações diretas para definir preços e rendimento da produção, e o tácito, em que as empresas de um setor definem indiretamente os preços e rendimentos da produção baseando-se na observação das ações competitivas umas das outras.

Outro tipo importante de estratégia cooperativa é a estratégia de cooperação no nível corporativo que é usada pela empresa para diversificar os produtos ofertados e/ou os mercados atendidos (Hitt, Ireland, \& Hoskisson, 2008). As estratégias cooperativas no nível corporativo mais comum são as alianças diversificantes, sinérgicas e o franchising. As alianças diversificantes e as alianças sinérgicas são usadas pelas empresas para diversificar e ampliar suas operações de outra forma a não ser por fusão ou aquisição.

Os mesmos autores esclarecem que uma aliança estratégica de diversificação é uma estratégia usada pelas empresas, no nível de negócios, a fim de se diversificarem em novos mercados ou produtos. Nesta aliança, as empresas compartilham recursos e capacitações para alcançar mercados e/ou produtos diferentes, embora estas alianças também possam servir para reduzir a diversificação em empresas que se diversificaram demais.

Tratando-se de estratégia de cooperação internacional, Mintzberg et al. (2006) mencionam que as alianças estratégicas internacionais (AEIs) são estratégias colaborativas, que incluem jointventure, participação minoritária, licenciamento, contrato sem participação societária, entre outros. Estas alianças têm como objetivos estratégicos o aprendizado, o apoio, a alavancagem das empresas envolvidas, a associação, a busca pela expansão e a restrição, que é a junção de parceiros para diminuir a pressão competitiva da concorrência, ou seja, diminuir a competitividade dos nãoparceiros.

Revista Ibero-Americana de Estratégia - RIAE, São Paulo, v. 11, n. 2, p. 34-69, mai./ago. 2012. 
Por fim, outra estratégia cooperativa utilizada pelas empresas é a estratégia em rede de cooperação. Mintzberg et al. (2006, p.207) conceituam rede como "um conjunto organizado de relações entre unidades de trabalho autônomas ou semi-autônomas para gerar um produto ou serviço completo para um cliente". A organização de empresa em redes pode assumir a característica de terceirização extrema, já que cada organização concentra-se em uma competência ou em uma parte da cadeia de valor.

Diante disso, a Figura 2 apresenta um resumo das principais estratégias de cooperação que podem ser encontradas no ambiente a ser pesquisado, além de servir de base para avaliar os tipos de estratégias utilizadas pelas indústrias investigadas.

Figura 2 - Estratégias de cooperação.

\begin{tabular}{|c|c|c|c|}
\hline ESTRATÉGIA & OBJETIVO & TIPOS & DESCRIÇÃO \\
\hline \multirow{4}{*}{$\begin{array}{l}\text { ESTRATÉGIA DE } \\
\text { COOPERAÇÃO } \\
\text { NO NÍVEL DE } \\
\text { NEGÓCIOS }\end{array}$} & \multirow{4}{*}{$\begin{array}{l}\text { A empresa junta } \\
\text { suas capacitações } \\
\text { e recursos com um } \\
\text { ou mais parceiros } \\
\text { para criar } \\
\text { vantagens } \\
\text { competitivas que } \\
\text { sozinha não } \\
\text { conseguiria, em } \\
\text { mercado de } \\
\text { produtos distintos }\end{array}$} & $\begin{array}{l}\text { Alianças estratégicas } \\
\text { complementares }\end{array}$ & $\begin{array}{l}\text { As empresas compartilham alguns de seus } \\
\text { recursos e capacitações de formas } \\
\text { complementares, com a finalidade de } \\
\text { desenvolver vantagens competitivas. }\end{array}$ \\
\hline & & $\begin{array}{l}\text { Estratégia de reação à } \\
\text { concorrência }\end{array}$ & $\begin{array}{l}\text { Utiliza alianças estratégicas para atacar e } \\
\text { reagir a ataques de rivais concorrentes }\end{array}$ \\
\hline & & $\begin{array}{l}\text { Estratégia de redução } \\
\text { das incertezas }\end{array}$ & $\begin{array}{l}\text { Usadas em mercados novos ou de ciclos } \\
\text { rápidos e na criação de novos produtos e } \\
\text { tecnologias para proteger a empresa contra } \\
\text { riscos e incertezas }\end{array}$ \\
\hline & & $\begin{array}{l}\text { Estratégia de redução } \\
\text { da concorrência }\end{array}$ & $\begin{array}{l}\text { Em um conluio, duas ou mais empresas } \\
\text { cooperam para aumentar os preços acima do } \\
\text { nível totalmente competitivo. }\end{array}$ \\
\hline \multirow{2}{*}{$\begin{array}{l}\text { ESTRATÉGIA DE } \\
\text { COOPERAÇÃO } \\
\text { NO NÍVEL } \\
\text { CORPORATIVO }\end{array}$} & \multirow{2}{*}{$\begin{array}{c}\text { Usada pela } \\
\text { empresa para } \\
\text { diversificar os } \\
\text { produtos ofertados } \\
\text { e/ou os mercados } \\
\text { atendidos }\end{array}$} & $\begin{array}{l}\text { Aliança estratégica de } \\
\text { diversificação }\end{array}$ & $\begin{array}{l}\text { As empresas compartilham recursos e } \\
\text { capacitações para alcançar mercados e/ou } \\
\text { produtos diferentes. }\end{array}$ \\
\hline & & Alianças sinérgicas & $\begin{array}{l}\text { Empresas compartilham recursos e } \\
\text { capacitações para diversificar ambas as } \\
\text { empresas participantes da aliança em um } \\
\text { negócio novo de forma sinérgica. }\end{array}$ \\
\hline $\begin{array}{l}\text { ESTRATÉGIA DE } \\
\text { COOPERAÇÃO } \\
\text { INTERNACIONAL }\end{array}$ & \multicolumn{3}{|c|}{$\begin{array}{l}\text { Empresas, com sede em países diferentes, associam alguns de seus recursos e capacitações a } \\
\text { fim de gerar vantagem competitiva }\end{array}$} \\
\hline
\end{tabular}

Revista Ibero-Americana de Estratégia - RIAE, São Paulo, v. 11, n. 2, p. 34-69, mai./ago. 2012. 
Fatores Condicionantes da Implementação de Estratégias Competitivas e Cooperativas: O Caso das Indústrias de Joias de Guaporé-RS

\section{ESTRATÉGIA EM REDE DE COOPERAÇÃO}

Fonte: Elaborado com base em Amato Neto (2000), Farias e Ramos (2009), Hitt, Ireland e Hoskisson (2008), Kanter (1997), Mintzberg et al. (2006), Motta (1995), Zawislak (2002).

Entende-se, com base na revisão feita sobre estratégias competitivas e cooperativas que o principal objetivo da empresa é alcançar um bom desempenho e adicionar valor aos seus stakeholders. Caso contrário, a empresa deve rever seu processo de gestão estratégica e corrigir os problemas que possam existir na formulação da estratégia, implementação, ou controle.

Para Tan, Shen e Langston (2012), não existe uma estratégia única que irá tornar uma empresa bem-sucedida para sempre. Segundo os autores, a avaliação periódica e revisão da estratégia de mudança do ambiente pode ajudar uma empresa a alcançar seus objetivos com mais eficiência.

\section{PROCEDIMENTOS METODOLÓGICOS}

Para atingir o objetivo, este estudo se classifica como exploratório e qualitativo, que se justifica pelo desconhecimento dos fatores que condicionam o desenvolvimento de estratégias competitivas e cooperativas nas indústrias de joias de Guaporé-RS.

Nesta pesquisa, a população utilizada foi constituída pelas indústrias produtoras de joias localizadas no município de Guaporé/RS. Conforme dados fornecidos pela Secretaria de Indústria e Comércio do município, em 2011, havia 138 empresas de joias cadastradas.

A amostra inicial foi de 35 empresas escolhidas, utilizando-se, para isso, os critérios de acessibilidade, intencionalidade e por conveniência, ou seja, as que se dispuseram participar da pesquisa. Após isto, foi disponibilizado um questionário que foi respondido pelo agente que define as estratégias ou conhecia e participava das decisões estratégicas internas, seja ele o proprietário, o diretor ou o gerente, onde se estipulou o prazo de 30 dias para retornarem o questionário preenchido. Cabe salientar que a aplicação do questionário deu-se sem a presença do pesquisador com o intuito de deixá-lo à vontade para imprimir sua opinião e diferentes pontos de vista. Transcorridos os 30 dias, retornaram apenas 22 questionários preenchidos que foram considerados no momento de se analisar os dados. 
Quanto ao instrumento empregado na coleta de dados, o questionário foi composto por perguntas abertas e de múltipla escolha, elaborado a partir das categorias de análise que se basearam nas Figuras 1 e 2, sendo elas:

a) Estratégias Competitivas - compreendem as manobras que as empresas adotam a fim de obter desempenho melhor do que seus concorrentes; e,

b) Estratégias Cooperativas - estratégias adotadas por empresas que unem esforços para atingir objetivos em comum.

Quanto à análise dos dados, estes foram analisados utilizando a técnica de análise de conteúdos das respostas dos questionários.

\section{ANÁLISE E INTERPRETAÇÃO DOS DADOS}

\subsection{CARACTERIZAÇÃO DAS EMPRESAS ESTUDADAS}

Para identificar as empresas participantes, utiliza-se a denominação de Empresa 1, Empresa 2, Empresa 3, e assim sucessivamente. Isto não acarreta perda dos resultados obtidos na pesquisa, resguardando sua identidade.

As empresas estudadas dedicam-se às diferentes etapas do processo produtivo, como mostra a Figura 3.

Figura 3 - Etapas do processo produtivo da jóia.

\begin{tabular}{|c|c|c|c|c|l|}
\hline ETAPA & $\begin{array}{c}\text { SOMENTE } \\
\text { BRUTO }\end{array}$ & $\begin{array}{c}\text { SOMENTE } \\
\text { BANHO } \\
\text { GALVÂNICO }\end{array}$ & $\begin{array}{c}\text { TODO } \\
\text { O PROCESSO }\end{array}$ & $\begin{array}{c}\text { PRESTAÇÃO } \\
\text { DE SERVIÇOS }\end{array}$ & OUTROS \\
\hline 1 & & & $\mathbf{X}$ & & \\
\hline 2 & & & $\mathrm{X}$ & & \\
\hline 3 & & & $\mathrm{X}$ & & \\
\hline 4 & & & $\mathrm{X}$ & & \\
\hline
\end{tabular}

Revista Ibero-Americana de Estratégia - RIAE, São Paulo, v. 11, n. 2, p. 34-69, mai./ago. 2012. 
Fatores Condicionantes da Implementação de Estratégias Competitivas e Cooperativas: O Caso das Indústrias de Joias de Guaporé-RS

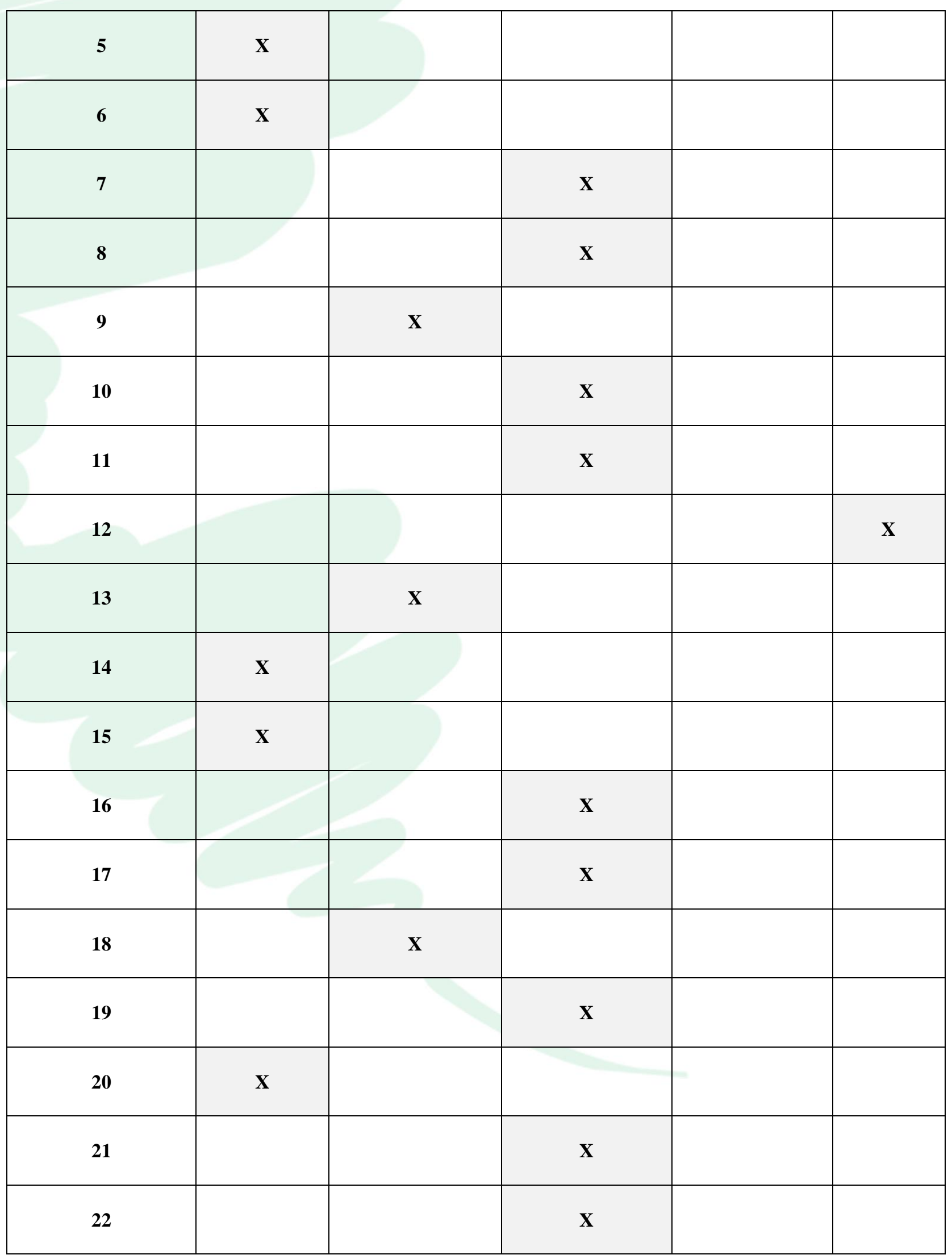

Fonte: Dados primários (2010).

Revista Ibero-Americana de Estratégia - RIAE, São Paulo, v. 11, n. 2, p. 34-69, mai./ago. 2012. 
Das 22 empresas participantes do estudo, 59\% dedicam-se a todo o processo produtivo da joia, ou seja, fabricam desde o bruto até o produto pronto. A outra parte das empresas pesquisadas dedica-se somente a uma parte do processo. Deste percentual, 23\% das empresas pesquisadas produzem somente peças brutas, e 14\% trabalham apenas com o banho galvânico das peças.

Nenhuma das empresas trabalha no ramo da prestação de serviço, e apenas uma não trabalha na fabricação da joia, exercendo a função de revenda do produto final.

Outro aspecto importante na análise das características das empresas é a relação entre o tempo de atuação, o porte da empresa e o número de funcionários. Estes dados estão expostos na figura 4.

Figura 4 - Características da empresas estudadas.

\begin{tabular}{|c|c|c|c|c|}
\hline \multicolumn{5}{|c|}{ CARACTERÍSTICAS DAS EMPRESAS ESTUDADAS } \\
\hline \multirow{2}{*}{ EMPRESA } & \multirow{2}{*}{$\begin{array}{l}\text { TEMPO DE ATUAÇÃO } \\
\text { (em anos) }\end{array}$} & \multirow{2}{*}{ PORTE } & \multicolumn{2}{|c|}{ No FUNCIONÁRIOS } \\
\hline & & & EFETIVOS & TERCEIRIZADOS \\
\hline 1 & 25 & Micro/pequeno porte & 32 & \\
\hline 2 & 04 & Micro/pequeno porte & 35 & \\
\hline 3 & 14 & Micro/pequeno porte & 32 & \\
\hline 4 & 70 & Médio porte & 100 & \\
\hline 5 & 18 & Micro/pequeno porte & 11 & 9 \\
\hline 6 & 12 & Micro/pequeno porte & 18 & 10 \\
\hline 7 & 04 & Micro/pequeno porte & 32 & \\
\hline 8 & 25 & Médio porte & 80 & \\
\hline 9 & 20 & Micro/pequeno porte & 5 & \\
\hline 10 & 35 & Médio porte & 75 & 25 \\
\hline
\end{tabular}

Revista Ibero-Americana de Estratégia - RIAE, São Paulo, v. 11, n. 2, p. 34-69, mai./ago. 2012. 
Fatores Condicionantes da Implementação de Estratégias Competitivas e Cooperativas: O Caso das Indústrias de Joias de Guaporé-RS

\begin{tabular}{|c|c|c|c|c|}
\hline 11 & 18 & Médio porte & 15 & \\
\hline 12 & 07 & Micro/pequeno porte & 6 & \\
\hline 13 & 16 & Micro/pequeno porte & 10 & \\
\hline 14 & 21 & Micro/pequeno porte & 13 & \\
\hline 15 & 10 & Micro/pequeno porte & 10 & 15 \\
\hline 16 & 22 & Médio porte & 71 & \\
\hline 17 & 20 & Micro/pequeno porte & 89 & \\
\hline 18 & 06 & Micro/pequeno porte & 25 & \\
\hline 19 & 21 & Médio porte & 67 & 24 \\
\hline 20 & 13 & Micro/pequeno porte & 2 & \\
\hline 21 & 33 & Médio porte & 50 & \\
\hline 22 & 13 & Micro/pequeno porte & 15 & \\
\hline
\end{tabular}

Fonte: Dados primários (2010).

Ao analisar os dados da figura 4, pode constatar-se que a média de tempo de atuação das empresas estudadas é de 19 anos, apresentando uma variação significativa. Esta variação pode ser percebida ao compararmos a Empresa 4, que possui 70 anos de mercado, com a Empresa 2 e Empresa 7, que possuem apenas 4 anos de atuação mercadológica.

Constatou-se também que das 22 empresas pesquisadas, sete são de médio porte, enquanto 15 são caracterizadas como micro ou pequenas. Ao relacionar o porte da empresa com o seu tempo de atuação no mercado, notou-se que entre as empresas de médio porte é de 32 anos. Esta média cai para 14 anos em empresas de micro ou pequeno porte, o que demonstra que as de maior porte são as que atuam a mais tempo no mercado.

Revista Ibero-Americana de Estratégia - RIAE, São Paulo, v. 11, n. 2, p. 34-69, mai./ago. 2012. 
Outra análise que pode ser feita é a comparação do número de funcionários efetivos e terceirizados. Notou-se que o número médio de funcionários efetivos variou significativamente, com uma média de 65 funcionários nas de médio porte, e 22 funcionários nas de pequeno porte.

Ao comparar o número de funcionários com os dados constantes na figura 3 , pode-se perceber que as empresas que atuam em somente uma parte do processo produtivo são, em geral, as que possuem menor número de funcionários. Além do mais, o porte destas empresas é menor, uma vez que todas as que atuam em somente uma etapa do processo são micro ou pequenas empresas.

Nesse sentido, pode-se dizer que das empresas que fabricam somente o bruto, o número médio de funcionários efetivos é de 11. Nas que somente trabalham com banho galvânico a média é de 13 funcionários, enquanto para as empresas que atuam em todo o processo produtivo este número se eleva para 53 funcionários. A Empresa 12 chama a atenção por não se dedicar ao processo produtivo, atuando na comercialização de produtos prontos e, mesmo assim, possuir seis funcionários em seu quadro pessoal.

Em relação ao uso de funcionários terceirizados, apenas cinco possuem mão de obra terceirizada, sendo que destas empresas, três são fabricantes somente de bruto e duas se dedicam a todo o processo produtivo. O número médio de funcionários terceirizados nas empresas de brutos é de 17 e nas que fabricam toda a joia a média é de 25 funcionários.

Quanto à terceirização, destaca-se a Empresa 15 em que o número de funcionários terceirizados é maior do que os efetivos. Além disso, observa-se que mais que a metade das empresas fabricantes de bruto utiliza a terceirização. Entre as empresas que se dedicam a todas as etapas do processo produtivo e que se valem da terceirização, todas são de médio porte, o que conduz ao entendimento de que a terceirização nestas empresas é vista como uma alternativa interessante em termos de investimentos internos no processo de produção.

\subsection{ANÁLISE DAS ESTRATÉGIAS COMPETITIVAS}

Segundo a revisão da literatura que traz a contribuição dos autores sobre as tipologias de estratégias competitivas, a figura 5 resume os tipos utilizados pelas empresas para competir no mercado.

Revista Ibero-Americana de Estratégia - RIAE, São Paulo, v. 11, n. 2, p. 34-69, mai./ago. 2012. 
Fatores Condicionantes da Implementação de Estratégias Competitivas e Cooperativas: O Caso das Indústrias de Joias de Guaporé-RS

Figura 5- Estratégias competitivas utilizadas pelas empresas pesquisadas.

\begin{tabular}{|c|c|c|c|c|c|c|c|}
\hline \multirow[b]{2}{*}{ EMPRESA } & \multirow{2}{*}{$\begin{array}{l}\text { LIDERANÇA } \\
\text { EM CUSTOS }\end{array}$} & \multirow[b]{2}{*}{ DIFERENCIAÇÃO } & \multirow{2}{*}{$\begin{array}{l}\text { LIDERANÇA } \\
\text { CUSTOS/ } \\
\text { FOCADA }\end{array}$} & \multirow{2}{*}{$\begin{array}{l}\text { DIFERENCIAÇÃO } \\
\text { FOCALIZADA }\end{array}$} & \multirow{2}{*}{$\begin{array}{c}\text { INTEGRADA } \\
\text { DE } \\
\text { LIDERANCCA } \\
\text { EM CUSTOS/ } \\
\text { DIFERENC. }\end{array}$} & \multicolumn{2}{|c|}{ DIVERSIFICAÇÃO } \\
\hline & & & & & & RELACIONADA & $\begin{array}{c}\text { NÃO } \\
\text { RELACIONADA }\end{array}$ \\
\hline 1 & & $\mathbf{X}$ & & & & & \\
\hline 2 & & $\mathbf{X}$ & & & & & \\
\hline 3 & & $\mathbf{X}$ & & & & & \\
\hline 4 & & $\mathbf{X}$ & & & & & \\
\hline 5 & & $\mathbf{X}$ & & & & $\mathbf{X}$ & \\
\hline 6 & & $\mathbf{X}$ & & & & & \\
\hline 7 & & $\mathbf{X}$ & & & & & \\
\hline 8 & & & & & $\mathbf{X}$ & & \\
\hline 9 & & & & & $\mathbf{X}$ & & \\
\hline 10 & & $\mathbf{X}$ & & & & & \\
\hline 11 & $\mathbf{X}$ & & & & & & \\
\hline 12 & & $\mathbf{X}$ & & & & & \\
\hline 13 & & & & & $\mathbf{X}$ & & \\
\hline 14 & & $\mathbf{X}$ & & & & & \\
\hline 15 & & & & $\mathbf{X}$ & & & \\
\hline 16 & & $\mathbf{X}$ & & & & & \\
\hline 17 & & $\mathbf{X}$ & & & & $\mathbf{X}$ & \\
\hline
\end{tabular}

Revista Ibero-Americana de Estratégia - RIAE, São Paulo, v. 11, n. 2, p. 34-69, mai./ago. 2012. 


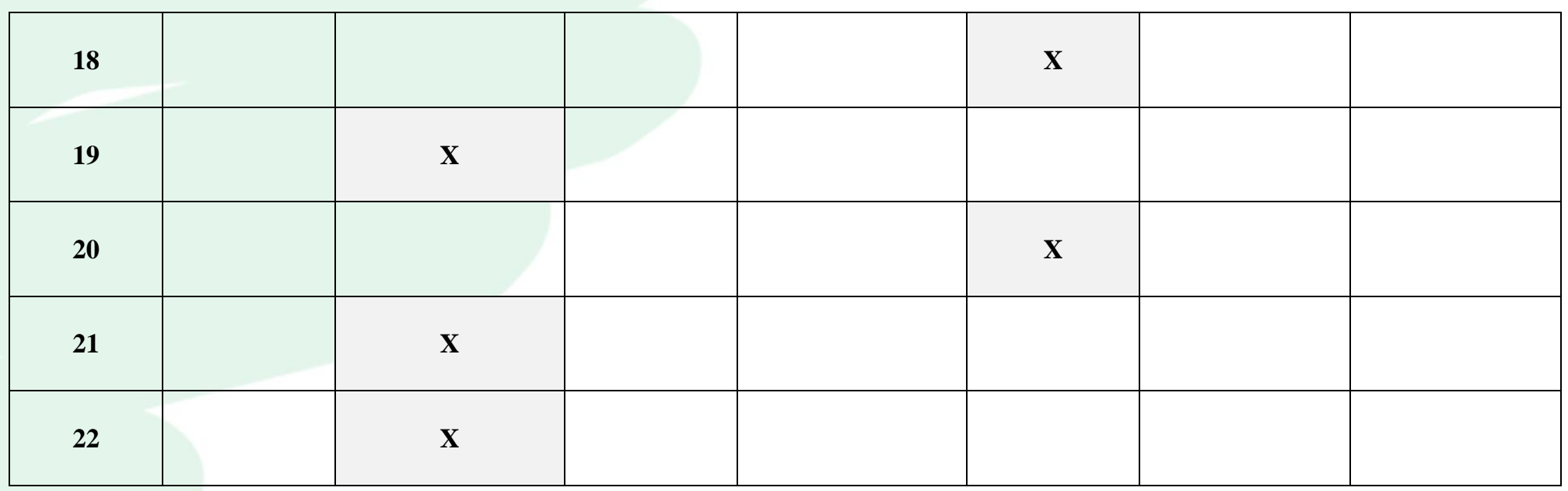

Fonte: Dados primários (2010).

Deste modo, a estratégia mais utilizada pelas empresas é a diferenciação, justificada pela exigência do mercado, em que as empresas competem como exigente, nesse processo os consumidores enfatizam produtos mais elaborados, com valor agregado, dispondo-se a pagar um valor mais elevado por peças que tenham um diferencial.

A segunda estratégia mais utilizada é a Integrada de Liderança em Custos e Diferenciação. Esta afirmação reforça a ideia anterior de que o mercado é exigente, denotando uma competitividade declarada no setor.

Em relação à Estratégia de Liderança em Custos e a de Diferenciação Focalizada, pode-se constatar que ambas foram citadas por apenas uma das empresas. A Estratégia de Liderança em Custos revela que no setor também há um nicho de mercado que absorve produtos de menor custo e padronizados, porém, este nicho de mercado é menor do que aquele que tem preferência por produtos diferenciados. E, no caso da Estratégia de Diferenciação Focalizada, entende-se que sua utilização se respalda também na exigência do mercado, sendo que a opção estratégica volta-se para a atuação em um segmento estreito em detrimento do mercado como um todo.

No que diz respeito à Estratégia de Diversificação, duas das empresas estudadas possuem mais de um negócio ou competem em mercados distintos. Ambas as empresas justificam a diversificação pela possibilidade de aumentar o ganho e o equilíbrio financeiro. Não foram investigados os tipos de negócios diversificados das duas empresas de joias.

Em relação ao produto fabricado pela empresa e a estratégia adotada, das cinco empresas que produzem somente bruto, três utilizam a Estratégia de Diferenciação e, das outras duas, uma afirmou utilizar a Estratégia de Diferenciação Focalizada e a outra a Estratégia Integrada de Liderança em Custos e Diferenciação.

Revista Ibero-Americana de Estratégia - RIAE, São Paulo, v. 11, n. 2, p. 34-69, mai./ago. 2012. 
Fatores Condicionantes da Implementação de Estratégias Competitivas e Cooperativas: O Caso das Indústrias de Joias de Guaporé-RS

Ao comparar estes dados com os constantes na figura 4, constata-se que as empresas que produzem o bruto e afirmam utilizar a Estratégia de Diferenciação estão há mais tempo no mercado do que as empresas que utilizam outra Estratégia Competitiva no Nível de Negócio. Os clientes (empresas) que compram peças brutas têm preferência por produtos que sejam diferenciados em detrimento de produtos padronizados.

Entre as empresas que se dedicam apenas ao banho galvânico, ou seja, aquelas que vendem o banho pronto para outras empresas ou compram o bruto e somente banham, todas afirmam utilizar a Estratégia Integrada de Liderança em Custos e Diferenciação. A forma encontrada por elas para obter sucesso no mercado é vender o produto a um valor não muito elevado, porém, com algum(ns) diferencial(is) como a qualidade, por exemplo.

Em relação às empresas que se dedicam a todo o processo produtivo, das 13 empresas entrevistadas 11 afirmaram utilizar a Estratégia de Diferenciação e, das outras duas restantes, uma afirmou fazer uso da Estratégia de Liderança em Custos e a outra da Estratégia Integrada de Liderança em Custos e Diferenciação. Em relação a isto, constatou-se que se as empresas se dedicam a todo o processo produtivo, o produto resultante é destinado ao consumidor final que enfatiza produtos diferenciados a um custo mais elevado, existindo também consumidores que preferem produtos mais baratos e padronizados.

\subsection{ANÁLISE DAS ESTRATÉGIAS COOPERATIVAS}

Nesta etapa da pesquisa, primeiramente foi questionado às empresas se elas cooperavam estrategicamente com outra(s) empresa(s), fornecedor(s) ou instituição(s), e de que forma esta cooperação ocorria.

Das empresas participantes do estudo, 17 afirmaram que cooperavam estrategicamente e cinco afirmaram não cooperar. Em Guaporé, isto ocorre por causa da grande competição, pois existem no local diversas empresas produzindo produtos iguais ou similares e atendendo o mesmo mercado. Assim, a cooperação surge como uma alternativa para as empresas guaporenses suprirem as suas deficiências individuais e conseguirem lidar com a forte concorrência.

Em se tratando da forma pela qual a cooperação ocorre, foram diversas as respostas obtidas, entre elas, as mais citadas foram a troca de informações citada por cinco empresas e a parceria com fornecedores, lembrada por duas empresas. Outras respostas foram: compra conjunta de matériaprima para ganhar poder de barganha, locação de parte da capacidade produtiva para desenvolver produtos para terceiros, desenvolvimento conjunto de novos produtos, auxílio na fabricação de

Revista Ibero-Americana de Estratégia - RIAE, São Paulo, v. 11, n. 2, p. 34-69, mai./ago. 2012. 
Ana Claudia Machado Padilha, Cristina Gallon \& Paloma de Mattos

algumas peças, empréstimo de materiais, parceria com o SEBRAE/SENAI para qualificação gerencial e treinamento da mão de obra e o desenvolvimento de parte do processo produtivo.

$\mathrm{Na}$ sequência, foram questionadas sobre a utilização de alguma(s) das Estratégias de Cooperação estudadas. As respostas obtidas são apresentadas na figura 6 .

Figura 6 - Estratégias de cooperação utilizadas pelas empresas pesquisadas.

\begin{tabular}{|c|c|c|c|c|c|c|c|c|c|}
\hline \multirow{2}{*}{ EMP. } & \multicolumn{2}{|c|}{$\begin{array}{l}\text { ALIANÇA ESTRATÉGICA } \\
\text { COMPLEMENTAR }\end{array}$} & \multirow{2}{*}{$\begin{array}{c}\text { REAÇ̃̃o } \\
\text { Á } \\
\text { CONCORRÊNCIA }\end{array}$} & \multirow{2}{*}{$\begin{array}{c}\text { REDUÇ̃̃̃ } \\
\text { DAS } \\
\text { INCERTEZAS }\end{array}$} & \multirow{2}{*}{$\begin{array}{c}\text { REDUÇÃOO } \\
\text { DA } \\
\text { CONCORRÊNCIA }\end{array}$} & \multirow{2}{*}{$\begin{array}{c}\text { ALIANÇA } \\
\text { DE } \\
\text { DIVERSIFIC. }\end{array}$} & \multirow{2}{*}{$\begin{array}{l}\text { ALIANCAS } \\
\text { SINÉRGICAS }\end{array}$} & \multirow{2}{*}{$\begin{array}{l}\text { COOPERAÇ̃̃o } \\
\text { INTERN. }\end{array}$} & \multirow{2}{*}{$\begin{array}{c}\text { REDE } \\
\text { DE } \\
\text { COOPERÇÃC }\end{array}$} \\
\hline & VERTICAL & HORIZONTAL & & & & & & & \\
\hline 1 & & & & & & & & & \\
\hline 2 & & & & & & & & & \\
\hline 3 & & $\mathrm{X}$ & & & & & & & \\
\hline 4 & & & & $\mathrm{X}$ & & & & & $\mathrm{X}$ \\
\hline 5 & & $\mathrm{X}$ & & & & & & & \\
\hline 6 & & $\mathrm{X}$ & & & & & & & \\
\hline 7 & & & & & & & & & \\
\hline 8 & $\mathrm{X}$ & $\mathrm{X}$ & & $\mathrm{X}$ & & & & & \\
\hline 9 & & & & & & & & & \\
\hline 10 & $\mathrm{X}$ & $\mathrm{X}$ & & & & & & & \\
\hline 11 & & $\mathrm{X}$ & & & & & & & \\
\hline 12 & & & & & & & & & \\
\hline 13 & & & & & & & & & \\
\hline 14 & & & & $\mathrm{X}$ & & & & & \\
\hline
\end{tabular}

Revista Ibero-Americana de Estratégia - RIAE, São Paulo, v. 11, n. 2, p. 34-69, mai./ago. 2012. 
Fatores Condicionantes da Implementação de Estratégias Competitivas e Cooperativas: O Caso das Indústrias de Joias de Guaporé-RS

\begin{tabular}{|c|c|c|c|c|c|c|}
\hline 15 & & & & & & \\
\hline 16 & & & & & & $X$ \\
\hline 17 & & & & & & \\
\hline 18 & $X$ & $X$ & & & & \\
\hline 19 & $X$ & $X$ & $X$ & & $X$ & \\
\hline 20 & $X$ & & & & & \\
\hline 21 & & & & $X$ & & \\
\hline 22 & & & & & & \\
\hline
\end{tabular}

Fonte: Dados primários (2010).

A Estratégia de Cooperação mais comum é a Aliança Estratégica Complementar Horizontal, mencionada por oito empresas e, a segunda mais usada, é a Aliança Estratégica Complementar Vertical, indicada por cinco empresas.

Quanto à Aliança Estratégica Complementar Horizontal, ressalta-se que a cooperação ocorre na etapa da fabricação, empréstimos de materiais, compartilhamento de parte do processo produtivo em outra empresa e parcerias com os fornecedores.

\subsection{ELEMENTOS DETERMINANTES DA ADOÇÃO DE ESTRATÉGIAS COMPETITIVAS E COOPERATIVAS}

O questionário aplicado às empresas contemplou também uma questão sobre os motivos que levaram a empresa a escolher determinada estratégia. Num primeiro momento, avalia-se os motivos que levaram a escolha da estratégia competitiva e, num segundo momento, descreve-se as expectativas na implementação da estratégia cooperativa.

A figura 7 especifica o tipo de estratégia competitiva adotada pelas empresas em razão das expectativas geradas quando de sua implantação. Cabe ressaltar que somente as Estratégias Competitivas de Nível de Negócios foram levadas em conta nesta análise, já que apenas duas

Revista Ibero-Americana de Estratégia - RIAE, São Paulo, v. 11, n. 2, p. 34-69, mai./ago. 2012. 
empresas afirmaram utilizar a Estratégia Competitiva no Nível Corporativo. Os valores presentes na figura 7 indicam quantas empresas indicaram a opção por cada Estratégia Competitiva. $\mathrm{O}$ total representa a soma de vezes que determinada expectativa foi citada, levando em consideração todas as estratégias.

Figura 7- Expectativas determinantes na escolha da Estratégia Competitiva.

\begin{tabular}{|c|c|c|c|c|c|c|}
\hline EXPECTRATIVA & $\begin{array}{l}\text { LIDERANCCA } \\
\text { EM CUSTOS }\end{array}$ & DIFERENCIAÇÃO & $\begin{array}{l}\text { LIDERANÇA } \\
\text { EM CUSTOS } \\
\text { FOCADA }\end{array}$ & $\begin{array}{l}\text { DIFERENCIAÇÃO } \\
\text { FOCALIZADA }\end{array}$ & $\begin{array}{c}\text { INTEGRADA DE } \\
\text { LIDERANÇA EM } \\
\text { CUSTOS E } \\
\text { DIFERENCIAÇÃO }\end{array}$ & TOTAL \\
\hline QUALIDADE & & 9 & & & & 9 \\
\hline DESIGN & & 2 & & & & 2 \\
\hline $\begin{array}{l}\text { SATISFAÇÃO DOS } \\
\text { CLIENTES }\end{array}$ & & 4 & & & & 4 \\
\hline $\begin{array}{l}\text { DIFERENCIAR-SE DOS } \\
\text { CONCORRENTES }\end{array}$ & & 4 & & & & 4 \\
\hline $\begin{array}{l}\text { FIDELIZAÇÃO DOS } \\
\text { CLIENTES }\end{array}$ & & 1 & & & & 1 \\
\hline $\begin{array}{l}\text { OBTER UM PREÇO } \\
\text { COMPETITIVO }\end{array}$ & 1 & & & & & 1 \\
\hline $\begin{array}{l}\text { PRODUZIR PRODUTOS } \\
\text { DIFERENCIADOS A UM } \\
\text { PREÇO ACESSÍVEL }\end{array}$ & & & & & 1 & 1 \\
\hline INOVAÇÃO & & 1 & & & & 1 \\
\hline $\begin{array}{l}\text { EXIGÊNCIA DO } \\
\text { MERCADO }\end{array}$ & & 3 & & & 1 & 4 \\
\hline ALTA CONCORRÊNCIA & & 1 & & 1 & 3 & 5 \\
\hline
\end{tabular}

Fonte: Dados primários (2010).

Entre as empresas que optaram pela Estratégia de Diferenciação (Figura 7), nove destacaram como motivo principal a necessidade de serem reconhecidas pela qualidade de seus produtos ou serviços. Também foram citados como fatores motivadores a busca pela satisfação dos clientes, a diferenciação da concorrência e a exigência crescente do mercado consumidor.

Revista Ibero-Americana de Estratégia - RIAE, São Paulo, v. 11, n. 2, p. 34-69, mai./ago. 2012. 
Fatores Condicionantes da Implementação de Estratégias Competitivas e Cooperativas: O Caso das Indústrias de Joias de Guaporé-RS

Assim, percebe-se que a maioria delas foca seus esforços na qualidade do produto como fator diferenciação da concorrência. Elas esperam que os clientes as valorizem pela qualidade, de tal forma que seja importante para eles adquirir este produto, mesmo a um preço mais elevado.

Quanto às cinco empresas que afirmaram utilizar a Estratégia Integrada de Liderança em Custos e Diferenciação, três afirmaram ter escolhido esta estratégia em razão da alta concorrência. Uma das empresas justifica a escolha mencionando: "O motivo é a alta concorrência, pois diferenciando o preço e diminuindo custos, a empresa fica mais competitiva e chama a atenção dos clientes".

Esta afirmação reforça a concepção de que a indústria de joias de Guaporé apresenta forte competitividade em razão do número de empresas instaladas no município.

$\mathrm{Na}$ Estratégia de Liderança em Custos, o motivo foi a obtenção de um preço mais competitivo comparado aos demais concorrentes.

A empresa que optou pela Estratégia Diferenciação Focalizada teve como expectativa destacar-se frente à alta concorrência. Diante da concorrência instalada no mercado de joias, a empresa optou por atender somente um nicho da indústria, suprindo-o com produtos diferenciados, buscando fidelizá-lo e desviar-se da concorrência.

No que tange às Estratégias de Cooperação, as respostas obtidas a respeito do motivo de sua escolha foram sistematizados e apresentados na figura 8. Vale destacar que cada empresa teve a opção múltipla de escolha.

Figura 8 - Motivos determinantes da adoção de estratégias cooperativas.

\begin{tabular}{|l|c|}
\hline \multicolumn{1}{|c|}{ RESPOSTAS } & NÚMERO DE CITAÇÕES \\
\hline Agilizar o lançamento de novos produtos & 1 \\
\hline Diferenciação dos produtos (agregar valor) & 2 \\
\hline Satisfação dos clientes & 1 \\
\hline Ampliar mercado & 3 \\
\hline Conseguir tecnologia mais avançada & 1 \\
\hline Exigência do mercado & 2 \\
\hline
\end{tabular}

Revista Ibero-Americana de Estratégia - RIAE, São Paulo, v. 11, n. 2, p. 34-69, mai./ago. 2012. 
Ana Claudia Machado Padilha, Cristina Gallon \& Paloma de Mattos

\begin{tabular}{|l|c|}
\hline Redução de custos & 4 \\
\hline Diminuição de riscos e incertezas & 2 \\
\hline
\end{tabular}

Fonte: Dados do estudo (2010).

A maioria das empresas respondeu que o motivo central da cooperação estratégica fundamenta-se na redução dos custos. A Empresa 16 destacou: "Os custos mais reduzidos são, basicamente, o que nos levou a participar de um "consórcio" entre seis empresas do ramo”. A Empresa 18 coopera estrategicamente mencionando: "a necessidade de conseguir matérias-primas com preço mais acessível". A Empresa $11 \mathrm{diz}$ cooperar a fim de "baixar o custo de investimento em equipamentos".

O entendimento da Empresa 16 sobre a participação em um "consórcio" (rede) para reduzir custos faz sentido. Ainda mais quando se avalia o fato de utilizar da Estratégia em Rede de Cooperação que gera redução de custos pelo compartilhamento de competências, recursos e capacidades.

O segundo motivo mais citado para estabelecer estratégias de cooperação fundamenta-se na necessidade de ampliação do mercado. Em relação a isso, pode-se destacar o posicionamento da Empresa 4: "Para ganhar mercado, sempre há uma chance maior desta forma". Isto leva a crer que a cooperação entre empresas é uma forma de conquistar mercados mais facilmente do que empresas que não cooperam, podendo gerar uma troca de conhecimento, avanço tecnológico e expansão do mercado.

Esta análise se torna interessante ao perceber que a Empresa 4 também utiliza a Estratégia de Redução das Incertezas ao desenvolver parceria com outras a fim de entrar em novos mercados ou criar novos produtos, protegendo-se assim contra riscos e incertezas. Adicionalmente, a mesma empresa utiliza também a Estratégia em Rede de Cooperação que fornece às empresas participantes acesso aos "parceiros de seus parceiros", contribuindo mais uma vez para a ampliação da chance de troca de recursos e capacitações e a expansão do mercado.

Revista Ibero-Americana de Estratégia - RIAE, São Paulo, v. 11, n. 2, p. 34-69, mai./ago. 2012. 
Fatores Condicionantes da Implementação de Estratégias Competitivas e Cooperativas: O Caso das Indústrias de Joias de Guaporé-RS

\subsection{ENTRAVES À IMPLEMENTAÇÃO DAS ESTRATÉGIAS}

O estudo também contemplou a identificação dos principais problemas enfrentados na implementação da estratégia e os resultados das respostas de escolha múltipla foram organizados na figura 9.

Figura 9 - Dificuldades percebidas na implementação da estratégia competitiva.

\begin{tabular}{|c|c|c|c|c|c|c|}
\hline DIFICULDADES & $\begin{array}{l}\text { LIDERANÇA } \\
\text { EM CUSTOS }\end{array}$ & DIFERENCIAÇÃO & $\begin{array}{l}\text { LIDERANÇA } \\
\text { EM CUSTOS } \\
\text { FOCADA }\end{array}$ & $\begin{array}{l}\text { DIFERENCIAÇÃO } \\
\text { FOCALIZADA }\end{array}$ & $\begin{array}{c}\text { INTEGRADA DE } \\
\text { LIDERANÇA EM } \\
\text { CUSTOS/DIFERENCIAÇÃo }\end{array}$ & TOTAL \\
\hline $\begin{array}{c}\text { CONCORRÊNCIA COM } \\
\text { PRODUTOS DE BAIXA } \\
\text { QUALIDADE }\end{array}$ & & 2 & & & 1 & 3 \\
\hline $\begin{array}{l}\text { CONCORRÊNCIA COM } \\
\text { PRODUTOS } \\
\text { IMPORTADOS }\end{array}$ & & 2 & & & & 2 \\
\hline $\begin{array}{l}\text { CONSTANTE } \\
\text { INOVAÇÃO DOS } \\
\text { PRODUTOS }\end{array}$ & & 2 & & & & 2 \\
\hline $\begin{array}{l}\text { FALTA DE MÃO DE } \\
\text { OBRA QUALIFICADA }\end{array}$ & & 2 & & & & 2 \\
\hline $\begin{array}{l}\text { CUSTOS ELEVADOS NA } \\
\text { CRIAÇÃO DE NOVOS } \\
\text { PRODUTOS }\end{array}$ & & 1 & & & & 1 \\
\hline $\begin{array}{c}\text { CÓPIA DE } \\
\text { MODELAGEM }\end{array}$ & & 1 & & & & 1 \\
\hline $\begin{array}{c}\text { PRODUÇÃO MAIS } \\
\text { LENTA }\end{array}$ & & 1 & & & & 1 \\
\hline $\begin{array}{l}\text { ADAPTAÇÃO DAS } \\
\text { PESSOAS ENVOLVIDAS } \\
\text { NO PROCESSO }\end{array}$ & & 1 & & & 1 & 2 \\
\hline $\begin{array}{l}\text { DIFICULDADES COM O } \\
\text { PESSOAL DE VENDAS }\end{array}$ & & 1 & & & 1 & 2 \\
\hline QUESTÃO TRIBUTÁRIA & & 2 & & & & 2 \\
\hline $\begin{array}{l}\text { RECONHECIMENTO NO } \\
\text { MERCADO }\end{array}$ & 1 & & & & & 1 \\
\hline $\begin{array}{c}\text { CONCORRÊNCIA } \\
\text { DESLEAL }\end{array}$ & & 1 & & & & 1 \\
\hline
\end{tabular}

Revista Ibero-Americana de Estratégia - RIAE, São Paulo, v. 11, n. 2, p. 34-69, mai./ago. 2012. 
Ana Claudia Machado Padilha, Cristina Gallon \& Paloma de Mattos

\begin{tabular}{|c|c|c|c|c|}
\hline $\begin{array}{l}\text { PRODUTO COM UM } \\
\text { CUSTO MAIS ELEVADO }\end{array}$ & 3 & 1 & & 4 \\
\hline $\begin{array}{l}\text { DEMONSTRAR A } \\
\text { QUALIDADE DO } \\
\text { PRODUTO }\end{array}$ & 2 & & & 2 \\
\hline $\begin{array}{l}\text { BAIXA MARGEM DE } \\
\text { LUCRO }\end{array}$ & & & 1 & 1 \\
\hline $\begin{array}{l}\text { INSTABILIDADE DA } \\
\text { MOEDA NACIONAL }\end{array}$ & 1 & & & 1 \\
\hline $\begin{array}{c}\text { PRODUTO } \\
\text { DIFERENCIADO COM } \\
\text { PREÇO COMPETITIVO }\end{array}$ & & & 1 & 1 \\
\hline
\end{tabular}

Fonte: Dados primários (2010).

Entre as empresas que optaram pela Estratégia de Diferenciação, o problema mais citado foi o elevado custo dos produtos, seguido pela concorrência de produtos de baixa qualidade, concorrência de produtos importados, necessidade de constantes inovações dos produtos, falta de mão de obra qualificada, carga tributária que onera o setor e a importância do cliente perceber a qualidade ou diferencial do produto.

A respeito da dificuldade da concorrência de produtos de baixa qualidade e de produtos importados, justifica a preocupação das empresas em demonstrar a qualidade do produto aos clientes. Se o cliente não perceber os reais atributos diferenciados do produto, como a qualidade, acabará optando por uma imitação de uma empresa rival que possua um preço mais baixo.

Nesse sentido, a Empresa 12 relata: "Em função da concorrência, é preciso provar a qualidade do produto". A Empresa 16 explica: "Sempre que atendemos um cliente novo é preciso dar ênfase ao produto e enfatizara qualidade”. Resumindo, se a qualidade não for percebida pelos clientes, eles irão comprar produtos semelhantes, porém com menor qualidade e a um preço mais baixo, como os importados, por exemplo.

Em relação ao elevado custo dos produtos, a Empresa 4 afirma que: "A necessidade permanente de lançamentos é muito complexo para o processo produtivo”. A Empresa 2 conclui que "Inovar sempre é mais complicado do que "copiar" produtos. É necessário buscar coisas novas e investir na criação constantemente".

Vale destacar que o entrave central para a empresa que opta pela Estratégia de Diferenciação Focalizada é o elevado custo de produção. O investimento em desenvolvimento de novos produtos diferenciados, exige investimentos em P\&D, tecnologia, infraestrutura e recursos humanos 
Fatores Condicionantes da Implementação de Estratégias Competitivas e Cooperativas: O Caso das Indústrias de Joias de Guaporé-RS

qualificados, gerando custos mais elevados do que a produção de produtos padronizados ou "cópia" de produtos, como relata a Empresa 2.

Em relação à tributação dos produtos, a Empresa 10 destaca: “a carga tributária, assim como a diferença de alíquotas de ICMS nos Estados e a extinção dos créditos de ICMS sobre a matéria-prima”. A Empresa 19 complementa ao sugerir que o problema se relaciona com " $a$ concorrência com produtos similares (importados) de baixo preço que se beneficia dos impostos e taxas".

A percepção da Empresa 19 remete à análise anterior da concorrência dos produtos importados com preços baixos. Devido ao benefício tributário (impostos e taxas), o produto importado acaba ficando mais barato do que o produto nacional. O principal problema é relativo aos produtos da China, que além do benefício fiscal, conseguem um menor custo que se justifica pela mão de obra barata, o que não é típico somente do setor de joias, mas de todos os produtos importados deste país.

Ainda analisando a questão fiscal, a Empresa 10 destacou as diferenças de alíquotas de ICMS entre os estados brasileiros. Isto faz com que o produto gaúcho fique mais caro do que o produto de outros estados que tem alíquotas menores, se constituindo, muitas vezes, como uma barreira tarifária para os produtos de Guaporé.

Em se tratando das empresas que afirmam utilizar a Estratégia Integrada de Liderança em Custos e Diferenciação, foram cinco os entraves citados: a concorrência de produtos de baixa qualidade, a adaptação das pessoas envolvidas no processo, as dificuldades com o pessoal de vendas, a baixa margem de lucro e a dificuldade de fabricar um produto diferenciado com preço competitivo.

Portanto, é difícil para as empresas conseguirem executar suas tarefas básicas, de tal forma que reduza os custos e, ao mesmo tempo, consiga produzir produtos que tenham atributos que sejam suficientemente diferenciados para criar valor para o cliente-alvo.

Nesse sentido, a Empresa 20 argumenta que o problema é “diferenciar o produto, utilizando matérias-primas diferenciadas, mas com preços competitivos, tendo em foco chamar a atenção do mercado". Nota-se que a preocupação é conseguir produzir produtos com custos relativamente mais baixos, com características diferenciadas, que sejam percebidas pelo cliente alvo e, assim, despertar o interesse do mercado.

Quanto à Estratégia de Liderança em Custos, a empresa que a utiliza destacou como principal dificuldade o reconhecimento do mercado. Isto leva ao entendimento de que para 
conseguir a preferência (reconhecimento) em relação aos concorrentes, a empresa tem de procurar agregar valor ao produto ou tentar vendê-lo a um preço ainda menor.

Em relação às Estratégias Cooperativas, a figura 10 sintetiza os principais problemas elencados pelas empresas que decidiram cooperar estrategicamente. Esta foi outra questão de múltipla escolha para os participantes da pesquisa.

Figura 10- Dificuldades percebidas na implementação das estratégias cooperativas.

\begin{tabular}{|l|c|}
\hline \multicolumn{1}{|c|}{ PROBLEMAS CITADOS } & NÚMERO DE CITAÇÕES \\
\hline Encontrar parceiros com o mesmo propósito & 3 \\
\hline Adaptação da empresa a estratégia & 2 \\
\hline Encontrar parceiros de confiança & 1 \\
\hline Unificar as ideias das empresas envolvidas & 2 \\
\hline Conseguir manter os parceiros & 1 \\
\hline Desigualdade de taxas e tributos em relação aos produtos externos & 1 \\
\hline Fazer aliança com empresas do mesmo segmento & 1 \\
\hline Nenhum problema & 2 \\
\hline
\end{tabular}

Fonte: Dados primários (2010).

O problema mais citado pelas empresas estudadas que utilizavam alguma Estratégia de Cooperação foi a dificuldade de encontrar parceiros com o mesmo propósito. Nesse sentido, percebeu-se que os interesses individuais das pessoas e a cultura das empresas envolvidas influenciam na formação de uma aliança de cooperação.

Outro aspecto que exerce influência na implementação de uma estratégia de cooperação é a unificação das ideias das empresas envolvidas. Entre as pesquisadas, a Empresa 16 esclarece que ocorre "apenas na sintonia inicial entre si, facilmente resolvida quando todos querem atingir o mesmo objetivo”. Assim, notou-se que esta dificuldade em unificar as ideias e os interesses das empresas envolvidas é facilmente resolvida quando o objetivo buscado é o benefício mútuo.

Revista Ibero-Americana de Estratégia - RIAE, São Paulo, v. 11, n. 2, p. 34-69, mai./ago. 2012. 
Fatores Condicionantes da Implementação de Estratégias Competitivas e Cooperativas: O Caso das Indústrias de Joias de Guaporé-RS

Puderam-se levantar percepções sobre a adaptação da empresa à estratégia cooperativa. A preocupação das empresas reside no desafio de conseguir adaptar a empresa ao projeto, sem perder o foco, ou seja, fazer com que todos os envolvidos compreendessem o que precisava ser feito e o fizessem, de tal forma, que o objetivo almejado com a implementação da estratégia fosse alcançado.

Uma resposta chama a atenção e merece uma análise mais minuciosa. A Empresa 19 mencionou a desigualdade de taxas e tributos dos produtos nacionais comparados aos externos. Assim como este é um problema na Estratégia Competitiva, ele aparece mais uma vez na implementação da Estratégia Cooperativa, respaldado pelo fato de esta empresa é a única dentre as pesquisadas que adota a Estratégia de Cooperação Internacional.

Finalizando esta análise, a Empresa 5 e a Empresa 10 destacaram não haver dificuldade na implementação da estratégia cooperativa. Isto leva ao entendimento de que a existência ou não de entraves na cooperação estratégica pode estar relacionado à cultura organizacional de cada empresa, bem como a forma com que cada estrategista tomador de decisão percebe e conduz as ações e planos deste tipo de estratégia.

\subsection{RESULTADOS DA IMPLEMENTAÇÃO DAS ESTRATÉGIAS COMPETITIVAS E COOPERATIVAS}

A pesquisa contemplou também os resultados obtidos quanto às Estratégias Competitivas e Cooperativas que são apresentados na figura 11.

Figura 11- Resultados obtidos na implementação da estratégia competitiva.

\begin{tabular}{|c|c|c|c|c|c|c|}
\hline RESULTADOS & $\begin{array}{l}\text { LIDERANÇA } \\
\text { EM CUSTOS }\end{array}$ & DIFERENCIAÇÃO & $\begin{array}{l}\text { LIDERANÇA } \\
\text { EM CUSTOS } \\
\text { FOCADA }\end{array}$ & $\begin{array}{l}\text { DIFERENCIAÇÃo } \\
\text { FOCALIZADA }\end{array}$ & $\begin{array}{c}\text { INTEGRADA DE } \\
\text { LIDERANÇA EM } \\
\text { CUSTOS/DIFERENCIAÇÃo }\end{array}$ & TOTAL \\
\hline $\begin{array}{c}\text { CONSOLIDAÇ̃̃̃O } \\
\text { DA MARCA }\end{array}$ & & 3 & & & & 3 \\
\hline $\begin{array}{l}\text { BOA ACEITAÇÃO } \\
\text { DO PRODUTO }\end{array}$ & & 1 & & & & 1 \\
\hline $\begin{array}{l}\text { FIDELIZAÇÃO } \\
\text { DOS CLIENTES }\end{array}$ & & 5 & & & & 5 \\
\hline $\begin{array}{c}\text { MAIOR } \\
\text { RENTABILIDADE }\end{array}$ & & 5 & & & 1 & 6 \\
\hline $\begin{array}{l}\text { DIMINUIÇÃO DOS } \\
\text { CUSTOS }\end{array}$ & & 1 & & & & 1 \\
\hline
\end{tabular}

Revista Ibero-Americana de Estratégia - RIAE, São Paulo, v. 11, n. 2, p. 34-69, mai./ago. 2012. 
Ana Claudia Machado Padilha, Cristina Gallon \& Paloma de Mattos

\begin{tabular}{|c|c|c|c|c|c|}
\hline $\begin{array}{l}\text { AUMENTO DAS } \\
\text { VENDAS }\end{array}$ & & 4 & 1 & 1 & 6 \\
\hline $\begin{array}{l}\text { CREDIBILIDADE } \\
\text { DOS CLIENTES }\end{array}$ & & & & 2 & 2 \\
\hline $\begin{array}{c}\text { REDUÇÃO DA } \\
\text { INADIMPLÊNCIA }\end{array}$ & & 2 & & & 2 \\
\hline $\begin{array}{l}\text { RECONHECIDOS } \\
\text { PELA QUALIDADE }\end{array}$ & & 4 & & & 4 \\
\hline $\begin{array}{c}\text { PREÇO } \\
\text { COMPETITIVO }\end{array}$ & 1 & & & & 1 \\
\hline $\begin{array}{l}\text { DIVERSIFICAÇÃO } \\
\text { DE CLIENTES }\end{array}$ & & 1 & & & 1 \\
\hline
\end{tabular}

Fonte: Dados primários (2010).

Nota-se que entre as empresas optantes pela Estratégia de Diferenciação, as respostas mais citadas pelas empresas pesquisadas foram a fidelização de clientes e o aumento da rentabilidade, cada uma citada por cinco empresas.

Dessa forma, entende-se que, se a Estratégia de Diferenciação for implantada com sucesso e a empresa conseguir diferenciar seu produto a tal ponto que o cliente perceba que o produto satisfaz suas necessidades de forma exclusiva e melhor do que o concorrente, a empresa tem grande potencial de fidelizá-lo. A partir disto, se a empresa aumentar os preços, o cliente, provavelmente, continuará comprando, e assim, conseguirá vender o produto mais caro e ter uma margem de lucro maior.

$\mathrm{Na}$ análise dos motivos que levaram as empresas a adotarem a Estratégia de Diferenciação, a maioria mencionou o reconhecimento pela qualidade. Aspectos relacionados com a satisfação dos clientes e diferenciação da concorrência também foram lembrados e, ao se relacionar estes motivos com os resultados que afirmam ter obtido, pode-se constatar que os objetivos foram alcançados. Assim, entende-se que se fidelizaram os clientes e diferenciaram-se da concorrência, isto ocorreu em razão dos clientes terem percebido o atributo diferenciado que o produto oferecia que, neste caso, é a qualidade. A satisfação dos clientes também está ligada à fidelização, já que um cliente será fiel a uma empresa se estiver satisfeito com o produto ou serviço oferecido por ela.

Entre as empresas que adotaram a Estratégia Integrada de Custos e Diferenciação, o resultado percebido por duas delas foi a conquista da credibilidade dos clientes, seguido pelo aumento das vendas e do faturamento. Acredita-se que a conquista da credibilidade dos clientes deu-se em razão de acreditaram no diferencial do produto e, assim, deram preferência em

Revista Ibero-Americana de Estratégia - RIAE, São Paulo, v. 11, n. 2, p. 34-69, mai./ago. 2012. 
Fatores Condicionantes da Implementação de Estratégias Competitivas e Cooperativas: O Caso das Indústrias de Joias de Guaporé-RS

detrimento aos demais concorrentes ao perceberem alguns atributos diferenciados a um menor preço. $\mathrm{O}$ aumento das vendas e do faturamento, provavelmente, tem relação com a conquista de uma parcela maior do mercado e do resultado dos esforços de reduzir os custos dos produtos e vendê-los a um preço mais acessível.

Analisando a empresa que adota a Estratégia de Liderança em Custos, o resultado da implementação da estratégia revelou-se no alcance de preços mais competitivos. No contexto do ambiente estudado, é possível identificar que o mercado que absorve estas joias padronizadas de menor custo é relativamente menor do que o mercado que absorve produtos diferenciados. Esta conclusão dá-se em razão do número de empresas optantes pela Estratégia de Diferenciação em detrimento da Estratégia de Custos. Se houvesse um mercado mais atraente, é possível que mais empresas optassem por esta estratégia.

Além do mais, se um cliente decide comprar uma joia é porque espera que o produto tenha alguma característica diferenciada, como qualidade superior e design diferenciado. Caso contrário, optaria por comprar uma bijouteria que possui um preço inferior e baixa qualidade em termos de durabilidade de uso.

Quanto à Estratégia de Diferenciação Focalizada, o resultado obtido com sua implemetação foi o aumento das vendas. Ao comparar este aspecto com o motivo de sua adoção, o de fugir da concorrência, pode-se constatar que, no geral, ele foi alcançado, uma vez que foi identificado o aumento das vendas conseguido pelo destaque perante a concorrência e o aumento da fatia de mercado.

Vale destacar que esta parte da análise deteve-se aos resultados mais citados, a fim de caracterizar o ambiente de forma geral, e não a partir de opiniões isoladas.

No que tange às Estratégias de Cooperação, as respostas obtidas sobre os resultados de sua implementação foram sistematizados na figura 12. Mais uma vez esta questão apresentava opções de escolha múltipla para os participantes da pesquisa.

Figura 12- Resultados obtidos na implementação de estratégias cooperativas.

\begin{tabular}{|l|c|}
\hline \multicolumn{1}{|c|}{ RESULTADOS } & NÚMERO DE CITAÇÕES \\
\hline Melhorar os produtos & 1 \\
\hline Agregar valor aos produtos & 2 \\
\hline
\end{tabular}

Revista Ibero-Americana de Estratégia - RIAE, São Paulo, v. 11, n. 2, p. 34-69, mai./ago. 2012. 
Ana Claudia Machado Padilha, Cristina Gallon \& Paloma de Mattos

\begin{tabular}{|l|l|}
\hline Mais rapidez na entrega & 2 \\
\hline Clientes satisfeitos & 1 \\
\hline Conquista de novos clientes & 1 \\
\hline Minimização dos custos & 2 \\
\hline Acesso a tecnologia de ponta & 1 \\
\hline Tornou-se mais competitiva & 1 \\
\hline Aumento na produção & 4 \\
\hline Aumento no número de produtos comercializados & 1 \\
\hline Aumento nas vendas & 1 \\
\hline Aumento do faturamento & 5 \\
\hline Diminuição de capacidade ociosa & 1 \\
\hline
\end{tabular}

Fonte: Dados primários (2010).

Segundo as empresas pesquisadas, o principal resultado obtido com a implementação de Estratégias Cooperativas foi o aumento no faturamento. Os outros resultados mais lembrados pelas empresas foram o aumento da produção, conseguir agregar valor ao produto, maior rapidez na entrega e minimização dos custos.

A Empresa 20 resume o que foi citado pela maioria: "Os resultados foram o aumento do lucro, a diminuição de custos, o aumento da capacidade de produção, a diminuição de riscos de poder entregar o produto mais rápido e de boa qualidade”. Percebe-se que o aumento da capacidade de produção, a redução de custos e a capacidade de entrega ágil do produto, são resultados desta complementaridade de competências. Quando melhoram suas competências individuais, as firmas tendem a ficar mais competitivas. $\mathrm{O}$ aumento do lucro das empresas optantes por alguma Estratégia de Cooperação pode ser visto, então, como fruto desta melhoria de competências.

Revista Ibero-Americana de Estratégia - RIAE, São Paulo, v. 11, n. 2, p. 34-69, mai./ago. 2012. 
Fatores Condicionantes da Implementação de Estratégias Competitivas e Cooperativas: O Caso das Indústrias de Joias de Guaporé-RS

Quando questionadas sobre os motivos que as impulsionaram quanto à implementação de Estratégias Cooperativas, as repostas mais lembradas foram: a redução dos custos, o intuito de ampliar o mercado, de diferenciar o produto (agregar valor), de diminuir os riscos e incertezas e da exigência do mercado. Ao analisar as duas respostas percebe-se que a redução dos custos, o intuito de agregar valor ao produto e de reduzir riscos e incertezas foram plenamente alcançados. Em relação à ampliação do mercado, entende-se que se houver um aumento no faturamento e na produção, provavelmente estará relacionada, além da redução de custos, a um ganho de mercado.

E é assim que se desenha o cenário competitivo instalado no município de Guaporé que abriga empresas que industrializam joias para o mercado interno e externo.

\section{CONSIDERAÇÕES FINAIS}

O objetivo deste estudo centrou-se na identificação e análise dos fatores condicionantes do desenvolvimento de estratégias competitivas e cooperativas nas indústrias de joias de Guaporé. Desta forma, a partir da revisão da literatura que trata do tema e da análise dos dados coletados, podem ser tecidas algumas ponderações a fim de elucidar o objetivo que motivou a realização da pesquisa.

No que tange às tipologias da Estratégia Competitiva de Nível de Negócios, a mais utilizada entre as empresas pesquisadas foi a Diferenciação. Neste sentido, as empresas utilizam, em sua maioria, a mesma estratégia competitiva para disputa de mercado e, mesmo diante das dificuldades citadas, conseguem se manter no setor e sustentar participação de mercado.

O mundo dos negócios está cada vez mais competitivo. As decisões são cada vez mais importantes e os lucros, por sua vez, menores. Isto força as empresas a serem mais ágeis e participativas no mercado. Não existe uma regra específica para este objetivo. Não existe estratégia certa ou errada. O objetivo principal é a busca crescente por novos mercados e alcance de uma vantagem competitiva sustentável.

Julga-se pertinente neste contexto de discussão a cooperação entre as empresas enquanto alternativa significativamente válida. Um elemento importante evidenciado pelas empresas foi a dinâmica como esta cooperação ocorre, sendo a troca de informações como o principal fator.

No entanto, pode-se observar que este nível de cooperação poderia evoluir à medida que no local existem várias empresas que, de certa forma, competem sozinhas. Aspectos como o compartilhamento de recursos, capacidades e competências essenciais poderiam ser mais bem 
aproveitados e aplicados em termos de competição sistêmica das empresas envolvidas no setor, mesmo que a dificuldade na cooperação seja a busca dos mesmos propósitos. Não se pode deixar de lado aspectos relacionados com a confiança entre os parceiros, elemento fundamental neste tipo de estratégia.

A escolha da estratégia certa determina o sucesso competitivo das empresas no mercado que se revela na obtenção dos retornos acima da média. O desenvolvimento e implantação de estratégias são elementos importantes para o sucesso das empresas, principalmente em ambientes altamente competitivos, pois fazem com que as ações estratégicas ocorram quando as condições do ambiente são mais propícias, aumentando, assim, as chances de êxito.

É importante para as empresas de joias estudadas a escolha da estratégia, seja ela competitiva ou cooperativa. E a estratégia mais eficaz para cada empresa é aquela fruto da equivalência das oportunidades e ameaças do ambiente externo e das possibilidades oferecidas pelos recursos, capacitações e competências essenciais exclusivos da empresa, não existindo assim um posicionamento estratégico universalmente ideal.

\section{REFERÊNCIAS}

Amato Neto, J. (2000). Redes de cooperação produtiva e clusters regionais: oportunidades para as pequenas e médias empresas. São Paulo: Atlas. Doi:10.1016/j.ijhm.2011.10.003

Chena, C., Chang, K. (2012). Diversification strategy and financial performance in the Taiwanese hotel industry. International Journal of Hospitality Management, 31, 1030-1032.

Farias, A. S. D., Ramos, F. S. (2009). Cooperação industrial: alternativa para a competitividade de micro e pequenas empresas. Revista Innovare, 8, 14-25. Recuperado em 17 de novembro, 2010, de

http://www.cescage.edu.br/site/pagina/arquivos/revista/innovare/artigos/33b8cooperacao_industr ial_alternativa_para_a_competitividade_de_micro_e_pequenas_empresas.pdf

Fuchs, C.; Diamantopoulos, A. (2010). Evaluating the effectiveness of brand-positioning strategies from a consumer perspective. European Journal of Marketing, 44(11), 1763 - 1786. Doi:10.1108/03090561011079873

Furlanetto, E. L. (2002). Formação das estruturas de coordenação nas cadeias de suprimentos estudo de caso em cinco empresas gaúchas. Tese de doutorado, Universidade Federal do Rio Grande do Sul, Porto Alegre, RS, Brasil.

Revista Ibero-Americana de Estratégia - RIAE, São Paulo, v. 11, n. 2, p. 34-69, mai./ago. 2012. 
Fatores Condicionantes da Implementação de Estratégias Competitivas e Cooperativas: O Caso das Indústrias de Joias de Guaporé-RS

Hitt, M. A., Ireland, R. D., \& Hoskisson, R. E. (2008). Administração estratégica: competitividade e globalização (2a ed.). São Paulo: Cengage Learning.

Kanter, R. M. (1997). Quando os gigantes aprendem a dançar. Rio de Janeiro: Campus.

Liu, H.; Hsu, C. (2011). Antecedents and consequences of corporate diversification: A dynamic capabilities perspective. Management Decision, 49(9), 1510-1534. Doi:10.1108/00251741111173961

Merlo, O., Lukas, B. A., Whitwell, G. J. (2012). Marketing's reputation and influence in the firm. Journal of Business Research, n.65, p.446-452. Doi:10.1016/j.jbusres.2011.03.002

Mintzberg, H., Ahlstrand, B., Lampel, J., Quinn, J. B. \& Ghoshal, S. (2006). O processo da estratégia: conceitos, contextos e casos selecionados (4a ed.). Porto Alegre: Bookman.

Motta, R. (1995). A busca da competitividade nas empresas. Revista de Administração de Empresas, 35(1), 12-16.

Nandakumar, M. K., Ghobadian, A., O'regan, N. (2011). Generic strategies and performance evidence from manufacturing firms. International Journal of Productivity and Performance Management, 60(3), p.222-251. Doi: 10.1108/17410401111111970

Porter, M. E. (1989). A vantagem competitiva das nações. Rio de Janeiro: Campus.

Tan, Y., Shen, L. \& Langston, C. (2012). Competition environment, strategy, and performance in the Hong Kong Construction Industry. Journal of Construction Engineering and Management, 138(3). Doi: 10.1061/(ASCE)CO.1943-7862.0000407

Zawislak, P. A. (2002). Modelo de Gestão para Alianças Estratégicas para PMEs. Anais do Simpósio de Gestão da Inovação Tecnológica, 22, Salvador, Bahia, Brasil.

Recebido: 30/04/2012

Aprovado: 27/06/2012

Revista Ibero-Americana de Estratégia - RIAE, São Paulo, v. 11, n. 2, p. 34-69, mai./ago. 2012. 